\title{
Decline of mumps antibodies in Type 1 (insulin-dependent) diabetic children and a plateau in the rising incidence of Type 1 diabetes after introduction of the mumps-measles-rubella vaccine in Finland
}

\author{
H. Hyöty ${ }^{1}$, M. Hiltunen ${ }^{1}$, A. Reunanen ${ }^{2}$, P. Leinikki ${ }^{3}$, T. Vesikari ${ }^{1}$, R. Lounamaa ${ }^{4}$, J. Tuomilehto ${ }^{4}$, H. K. Åkerblom ${ }^{5}$, \\ and the Childhood Diabetes in Finland Study Group*
}

${ }^{1}$ Department of Biomedical Sciences, University of Tampere, Tampere, Finland
2 Research and Development Unit at the Social Insurance Institution, Helsinki, Finland
${ }^{3}$ HIV-department, National Public Health Institute, Helsinki, Finland
${ }^{4}$ Department of Epidemiology, National Public Health Institute, Helsinki, Finland
${ }^{5}$ The Children's Hospital, Second Department of Paediatrics, University of Helsinki, Helsinki, Finland

Summary. A nationwide mumps-measles-rubella vaccination was introduced in 1982 in Finland to children aged 1.5 to 6 years and since then mumps has virtually disappeared in the country. We investigated whether this rapid epidemiological change had any impact on antibody activity against mumps virus in Type 1 (insulin-dependent) diabetic children or on the incidence of Type 1 diabetes in Finland. Two casecontrol series were collected before (series I and II) and three series after (series III-V) the introduction of the vaccination. IgA class mumps antibody levels were significantly higher in Type 1 diabetic children than in matched control children in the first two but not in the three later series. IgG class antibody levels were similar in patients and control subjects in the first two series but significantly lower in patients than in control subjects in the three later series. The overall incidence of Type 1 diabetes in $0-14$-year-old children in- creased until 1987 but remained about the same during 1988 1990. In 5-9-year-old children no further increase in Type 1 diabetes was seen since 1985 , whereas in $0-4$-year-old children the incidence continued to rise until 1990 . The results suggest that the elimination of natural mumps by mumps-measles-rubella vaccination may have decreased the risk for Type 1 diabetes in Finland; a possible causal relationship is substantiated by the observed concomitant decrease in mumps antibody levels in diabetic children. However, further studies are required to determine if the vaccine virus, like natural mumps, could trigger the clinical onset of Type 1 diabetes in young children.

Key words: Mumps, mumps antibodies, mumps-measlesrubella vaccination, Type 1 (insulin-dependent) diabetes mellitus.
The role of mumps in the pathogenesis of Type 1 (insulindependent) diabetes mellitus has been suggested in several studies, but as yet a causal relationship has not been established. The incidence of Type 1 diabetes has been shown to increase 2-4 years after mumps epidemics [1-4] and, in individual cases, mumps infections have been documented before the clinical onset of Type 1 diabetes more often than would be expected [5]. Mumps virus is also able to infect pancreatic beta cells in culture $[6,7]$ and increase the amount of HLA class I molecules on infected beta cells [7]. Induction of islet-cell antibodies has also been described in association with mumps [8-11].

We have previously reported in two case-control studies $[1,12]$ elevated levels of serum IgA class mumps virus antibodies in Type 1 diabetic subjects, a phenomenon which has been confirmed by other investigators [13]. The introduction of mumps-measles-rubella (MMR) mass-vaccination in 1982 in Finland has resulted in the vir-

* See Acknowledgements tual disappearance of natural mumps [14]. In the present study we describe that after the introduction of MMR vaccination $\operatorname{IgA}$ antibody levels to mumps virus were no longer elevated in Type 1 diabetic patients compared to control subjects and mumps IgG antibody levels were lower than in control subjects, indicating that the lack of exposure to natural mumps is reflected by decreased amounts of mumps antibodies. We have attempted to correlate the serological findings to data on the incidence of new cases of Type 1 diabetes in Finland, which after many years of steady increase, may have reached a plateau during recent years.

\section{Subjects and methods \\ Epidemiology of mumps}

Annual numbers of mumps cases in Finland were obtained from the yearly reports on infectious diseases compiled by the Finnish National Board of Health. These figures include both serologically con- 


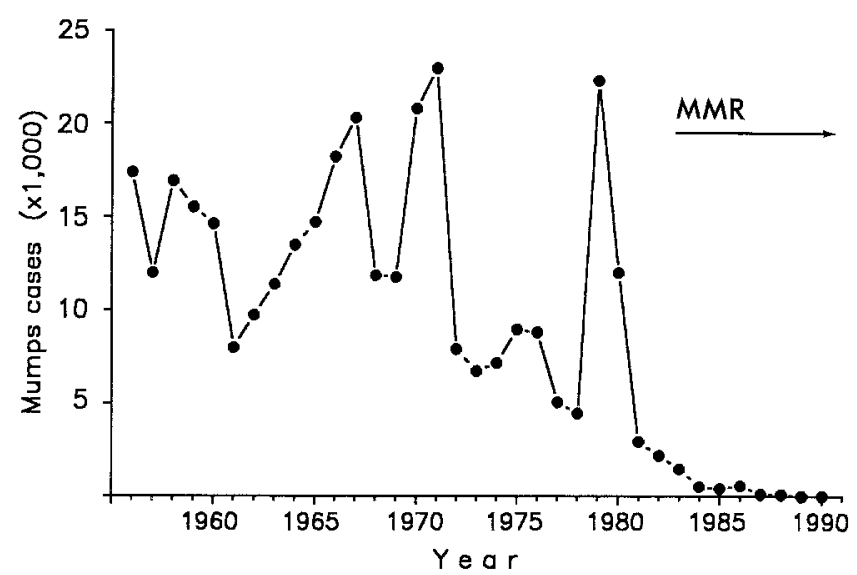

Fig.1. The annual number of mumps cases reported from the health centres and hospitals in Finland during 1956-1990. The time of the implementation of mumps-measles-rubella (MMR) vaccination is indicated

firmed cases as well as cases diagnosed only clinically. In addition, data on serologically confirmed mumps cases were obtained from the annual reports of the virological laboratories in Finland for the years 1977-1990.

\section{$M M R$ vaccination}

Vaccination with the trivalent mumps-measles-rubella (MMR) vaccine was started in Finland in November 1982 in children at the age of 14 18 months (first dose) and 6 years (second dose). To reach coverage of the target population sooner children who were more than 18 months but less than 6 years old were also vaccinated starting from April 1983. The overall coverage in the target population has continuously been over $95 \%[14,15]$. The vaccine (Virivac; Merck, Sharp Dohme \& Moraten, Rahway, NJ, USA) contains live attenuated mumps (Jeryl Lynn B strain), measles (Enders Edmonston B, strain) and rubella (RA 27/3 strain) viruses.

\section{Case-control series}

Five separate case-control series of sera were collected in different time periods. Series I and II were collected before the MMR vaccination programme, but soon after an extensive mumps epidemic in 1980, and series III, IV and V after the introduction of MMR vaccination. The sera from a patient and the corresponding control child were taken with no more than a 4-month interval.

Series I consisted of 210 Type 1 diabetic subjects treated at the Department of Paediatrics, University of Tampere; the sera were collected during 1980-1981. The mean duration of diabetes was 5 years and the mean age 13 years (range 2 to 19 years). The control children in this series were carefully matched according to age and sex, and were healthy schoolchildren living in the same area as the patients. The collection of this case-control series has been described earlier in detail [12].

Series II included 107 newly-diagnosed Type 1 diabetic children in 1980-1983; the sera were collected within 1 week after diagnosis. These patients were from the departments of paediatrics of the five medical schools in Finland (Helsinki, Kuopio, Oulu, Tampere and Turku) and their mean age was 9 years (range 1-16 years). Control subjects were carefully matched according to age, sex and residence-area, and consisted either of healthy children living in the neighbourhood of the corresponding patient $(n=62)$, or of hospitalized children who did not have autoimmune or malignant diseases $(n=45)$. This series has also been described earlier in detail [1].
Series III consisted of 54 newly-diagnosed patients from whom the serum was taken within 1 week after the diagnosis of Type 1 diabetes in the Department of Paediatrics, University of Tampere in 1985-1987. The mean age of this group was 8.5 years (range 117 years). The control children had been admitted to the same hospital for elective minor surgical operations. They were carefully matched for age and sex and had no autoimmune diseases or malignancies [16].

Series IV was collected as a part of the Childhood Diabetes in Finland (DiMe) -project in 1986-1989. Sera were taken from 93 patients who were living in different parts of the country and were younger than 7 years within 1 week after the diagnosis of Type 1 diabetes. Control children were matched for age and sex and were selected randomly from the Official Finnish Population Register. A detailed description of this project has been published earlier [17].

Series V was collected in 1986-1989 and contained 169 patients from the DiMe project and 169 sibling control children who were matched for age and sex. The age difference in these pairs was less than 2 months and the difference in the sampling date less than 1 month. The mean age of patients was 9 years (range $3-15$ years). Also these samples were taken within 1 week after the diagnosis of diabetes [17].

\section{Antibody studies}

Serum IgG and IgA class mumps antibody levels were measured by a four-layer modification of ELISA as previously described [12]. In series I and II a commercially available mumps virus antigen (Mumps Orivir; Orion Diagnostica, Mankkaa, Finland) was originally used as an ELISA antigen $[1,12]$. In series III, IV and $V$ the mumps virus antigen was prepared according to the principles previously described [18]. Briefly, allantoic fluid from infected chicken embryos was collected and, after crude centrifugation and filtration through a $450 \mathrm{~nm}$ filter, the supernatant was concentrated by a hollow-fibre liquid concentrator (Amicon; Grace Company, Mass., USA). The virions were pelleted by centrifugation through $30 \%$ sucrose layer in phosphate buffered saline ( $\mathrm{pH} 7.2$ ) onto a $50 \%$ sucrose cushion $\left(100,000 \mathrm{~g}, 120 \mathrm{~min}\right.$ at $\left.4{ }^{\circ} \mathrm{C}\right)$. In addition to series III-V also a proportion of series I and II ( 88 pairs and 42 pairs, respectively) were analysed using this purified antigen and the same ELISA procedure toexclude possible antigen-dependent differences. Antibody levels were expressed in enzyme immunoassay units (EIU) which show the relative antibody activity of the sample compared to positive and negative reference sera [12]. Coxsackie B4 virus (reference strain from World Health Organisation) antigen was purified from infected Vero cells and used in ELISA as previously described [19].

\section{Incidence of Type 1 diabetes}

The incidence data for Type 1 diabetes in children were derived from a national register maintained by the Social Insurance Institution, based on an allowance for free insulin treatment $[20,21]$. The annual incidence rates were based on all new cases of diabetes in children aged 0-14 years in Finland in 1966-1990 registered by the Social Insurance Institution. Because of rather large year-to-year fluctuation we used means of 3 or 4 consecutive years in the present analyses. In order to depict differences in diabetes risk by birth cohorts, cumulative incidence was calculated from the number of all children born during defined years and manifesting diabetes at the age of $0-4$ or 7-9 years according to the drug registry data and using all children born in the same years as denominator.

\section{Statistical analysis}

Paired Student's $t$-test was used in comparisons of paired data and non-parametric statistics (Mann-Whitney U-test) for other analyses. The age-adjustment in computing the annual and mean annual in- 
cidence rates was done by the direct method using the 5-year age group distribution of all children in Finland at the end of 1974 as the reference population. In the adjustment of the cumulative incidence rates the weights were based on the distribution of sizes of the birth cohorts.

\section{Results}

\section{Epidemiology of mumps}

After mumps epidemics during 1970 and 1971 a relatively long low-incidence period followed in Finland and was, in turn, followed by an extensive mumps epidemic in 1979 1980 (Fig. 1). In November 1982 a MMR mass-vaccination programme was introduced (see Subjects and methods). Since then the number of mumps cases has rapidly decreased and no epidemics have occurred (Fig. 1). The number of reported mumps cases was very low in 19841990 and an almost complete eradication has been achieved.

\section{Mumps virus antibodies in Type 1 diabetic subjects}

Mumps IgA antibody levels in the first two series, which were collected before the MMR vaccination soon after the extensive mumps epidemic in 1979-1980 were significantly higher in patients than in control children (Table 1, Fig. 2). However, in later series which were collected after the MMR vaccination had been initiated (series III-V) the mumps IgA levels were not different between patients and control children. IgG class mumps antibodies were similar in patients and control children in series I and II, but were significantly lower in patients than in control children in series III-V (Table 1, Fig. 2).

The patients and control children in series II were reanalysed using the same antigen and methods as in series III-V. Also in these analyses the patients had elevated levels of IgA class mumps virus antibodies compared to control children (mean EIU \pm SEM: $21 \pm 3$ vs $10 \pm 2$, $p<0.01$ ), while IgG levels did not differ between the groups ( $29 \pm 4$ vs $28 \pm 4$ ). IgA or IgG class antibody levels against coxsackie $B 4$ virus antigen showed no such decline in series III-V.

\section{Incidence of Type I diabetes}

The overall incidence of Type 1 diabetes in 0-14-year-old children steadily increased from 1966 to 1987 (Fig. 3). Two small peaks were observed, one in 1970-1972 and the other in 1982-1984, which both were preceded by an epidemic of mumps a few years earlier, in 1966-1967 and 1970-1971 as well as in 1979-1980. These two peaks in diabetes incidence rates were observed in both sexes and were more marked in 5-14-year-old than in very young (0-4-year-old) children (Fig. 4). After the implementation of MMR vaccination the increasing trend in the incidence of Type 1 diabetes continued until 1988-1990, 6 years after the initiation of MMR vaccination and al-
Table 1. The average serum $\operatorname{Ig} \mathrm{A}$ and $\operatorname{Ig} G$ class mumps antibody levels (mean EIU \pm SEM) in Type 1 diabetic subjects and matched control subjects in five different patient series (I-V)

\begin{tabular}{llllll}
\hline Series $^{\mathrm{a}}$ & $\begin{array}{l}\text { Time } \\
\text { period }\end{array}$ & $\begin{array}{l}\text { Antibody } \\
\text { class }\end{array}$ & $\begin{array}{l}\text { Diabetic Control } \\
\text { patients }\end{array}$ & subjects & $p$ value \\
\hline I $(n=219)$ & $1980-1981$ & $\operatorname{IgA}$ & $21 \pm 2$ & $14 \pm 2$ & $<0.01$ \\
& & $\operatorname{IgG}$ & $40 \pm 2$ & $40 \pm 2$ & $\mathrm{NS}$ \\
II $(n=107)$ & $1980-1983$ & $\operatorname{IgA}$ & $16 \pm 3$ & $9 \pm 2$ & $<0.02$ \\
& & $\operatorname{IgG}$ & $28 \pm 3$ & $27 \pm 3$ & $\mathrm{NS}$ \\
III $(n=54)$ & $1985-1987$ & IgA & $10 \pm 2$ & $8 \pm 2$ & $\mathrm{NS}$ \\
& & $\operatorname{IgG}$ & $32 \pm 3$ & $46 \pm 4$ & $<0.005$ \\
IV $(n=93)$ & $1986-1989$ & $\operatorname{IgA}$ & $2 \pm 1$ & $3 \pm 1$ & $\mathrm{NS}$ \\
& & $\operatorname{IgG}$ & $24 \pm 2$ & $33 \pm 2$ & $<0.01$ \\
V $(n=169)$ & $1986-1989$ & $\operatorname{IgA}$ & $6 \pm 1$ & $6 \pm 1$ & $\mathrm{NS}$ \\
& & $\operatorname{IgG}$ & $29 \pm 2$ & $36 \pm 2$ & $<0.005$ \\
\hline
\end{tabular}

The number of patient-control pairs is shown in parentheses. EIU, Enzyme immunoassay unit

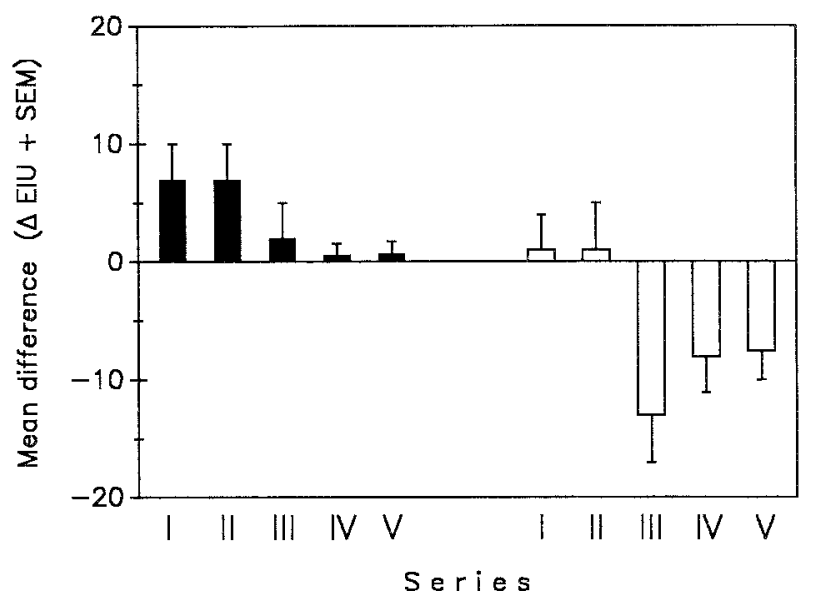

Fig. 2. The difference of $\operatorname{IgA}(\boldsymbol{\square})$ and $\operatorname{Ig} G(\square)$ mumps antibody levels between Type 1 diabetic subjects and corresponding control subjects (mean difference/EIU \pm SEM) in the five case-control series (I--V). Positive values indicate higher antibody levels in patients than in control subjects. EIU, Enzyme immunoassay unit

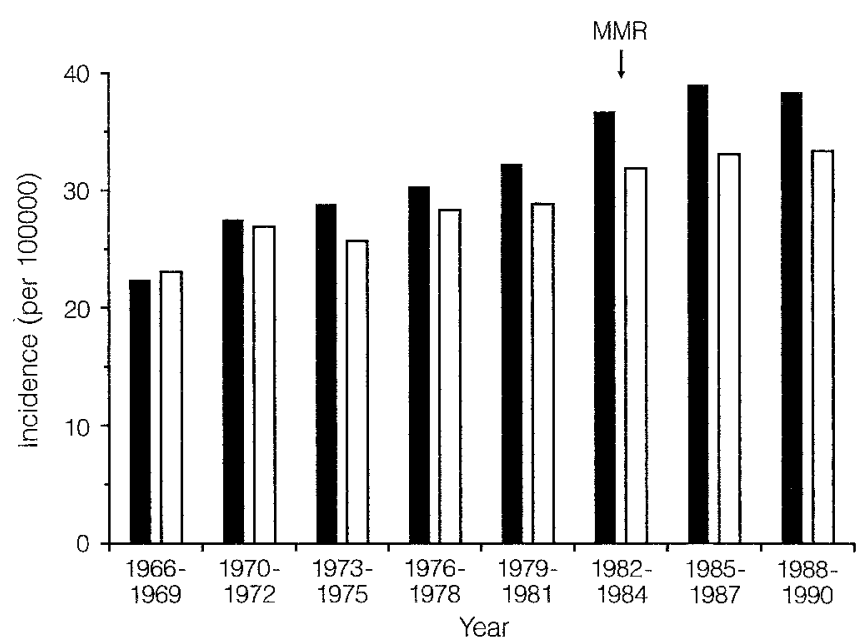

Fig.3. Age-adjusted mean annual incidence (per 100,000) of Type 1 diabetes in 0-14-year-old Finnish children by time period in boys

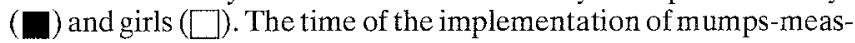
les-rubella (MMR) vaccination is indicated 


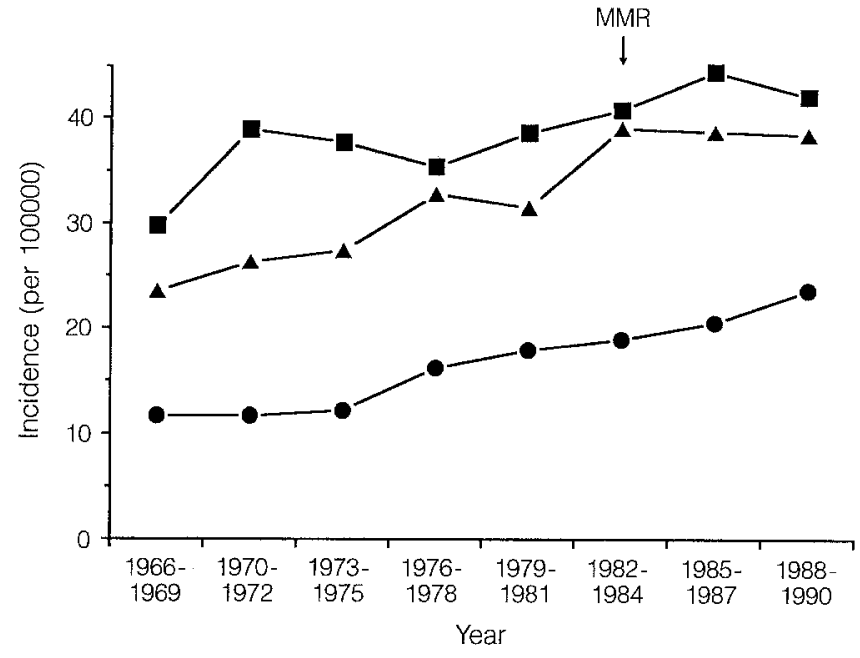

Fig.4. Age-adjusted mean annual incidence (per 100,000) of Type 1 diabetes in Finnish children by time period in different age groups ( - 0-4-year-old; $\wedge$ - $\Delta$ 5-9-year-old, $\square-\square$ 10-14-year-old children). The time of the implementation of mumps-measles-rubella (MMR) vaccination is indicated

most 10 years after the last mumps epidemic, when it seemed to plateau (Fig. 3). In very young children (04 year-old), however, the incidence continued to rise also in 1988-1990 (Fig. 4).

Cumulative incidence of Type 1 diabetes was analysed in different birth cohorts (Tables 2 and 3 ) which had presumably been exposed either to natural mumps or to MMR vaccination only. Among the children contracting diabetes at the age of 7-9 years (born 1979-1981), who were no longer exposed to natural mumps but had had vaccinations, a slightly lower cumulative incidence of Type 1 diabetes than in the two previous birth cohorts was found (Table 2). This difference was not, however, statistically significant. In the 0-4-year-old children, born after the introduction of the vaccine, a higher cumulative incidence of Type 1 diabetes than in the non-vaccinated cohorts was seen (Table 3).

\section{Discussion}

We have shown that during a non-epidemic period after the nationwide MMR vaccination was introduced in Finland serum mumps IgA antibodies in patients with Type 1 diabetes have decreased from elevated to normal levels and IgG antibodies from normal to abnormally low levels. The decreasing trend in $\operatorname{IgA}$ and $\operatorname{IgG}$ class antibody profiles in patients was seen also when the sera from the previous series were re-analysed with exactly the same methods that were used in the later series suggesting that these changes were not due to technical differences in our ELISA tests.

The selection of individuals for matched control children could explain the differences in antibody levels. However, this seems unlikely as all control children were carefully matched for age and sex and the age-distribution overlapped considerably in different series. On the other hand, differences in the history of MMR vaccinations between these series could also be related to the differences in antibody profiles. We are analysing the material in this respect and our preliminary observations suggest that this is not the case; the number of MMR vaccinations was not different between patients and control children, and the antibody abnormalities in patients were observed following both MMR vaccinations and natural infections (M. Hiltunen and H. Hyöty, unpublished observations). It has also been previously shown that mumps antibody levels in

Table 2. Cumulative incidence (means and 95\% confidence intervals) of Type 1 diabetes (per 100,000) in children aged 7-9 years in different birth cohorts in Finland

\begin{tabular}{|c|c|c|c|c|c|c|}
\hline $\begin{array}{l}\text { Birth } \\
\text { cohort }\end{array}$ & $\begin{array}{l}\text { Diagnosis of } \\
\text { diabetes }\end{array}$ & $\begin{array}{l}\text { MMR } \\
\text { vaccination }\end{array}$ & $\begin{array}{l}\text { Exposure to } \\
\text { mumps epidemics }\end{array}$ & Boys & Girls & All \\
\hline $1970-1972$ & $1977-1981$ & - & + & $110.9 \quad(89.3-132.5)$ & $93.8 \quad(73.6-114.0)$ & $102.6 \quad(87.9-117.3)$ \\
\hline $1973-1975$ & $1980-1984$ & - & + & $122.9(100.6-145.2)$ & $103.5 \quad(82.5-124.5)$ & $113.5 \quad(98.2-128.8)$ \\
\hline 1979-1981 & 1986-1990 & + & - & $115.9 \quad(94.7-137.1)$ & $102.7 \quad(82.3-123.1)$ & $109.4 \quad(94.7-124.1)$ \\
\hline
\end{tabular}

MMR, Mumps-measles-rubella

Table 3. Cumulative incidence (means and $95 \%$ confidence intervals) of Type 1 diabetes (per 100,000) in children aged $0-4$ years in different birth cohorts in Finland

\begin{tabular}{|c|c|c|c|c|c|c|}
\hline $\begin{array}{l}\text { Birth } \\
\text { cohort }\end{array}$ & $\begin{array}{l}\text { Diagnosis of } \\
\text { diabetes }\end{array}$ & $\begin{array}{l}\text { MMR } \\
\text { vaccination }\end{array}$ & $\begin{array}{l}\text { Exposure to } \\
\text { mumps epidemics }\end{array}$ & Boys & Girls & All \\
\hline $1973-1975$ & $1973-1979$ & - & - & $79.5 \quad(61.5-97.5)$ & $84.6(65.6-103.6)$ & $82.0 \quad(68.9-95.1)$ \\
\hline $1976-1980$ & $1976-1984$ & $(+)$ & + & $113.1^{\mathrm{a}}(97.0-129.2)$ & $92.3(78.2-106.4)$ & $102.9^{\mathrm{b}}(91.9-113.9)$ \\
\hline $1984-1986$ & $1984-1990$ & + & - & $122.7(100.8-144.7)$ & $115.0(93.2-136.8)$ & $119.0(103.5-134.5)$ \\
\hline $1973-1980$ & $1973-1984$ & $-(+)$ & + & $101.0 \quad(88.9-113.2)$ & $89.5(77.7-101.3)$ & $95.4 \quad(87.0-103.8)$ \\
\hline $1981-1986$ & $1981-1990$ & + & - & $123.1^{\mathrm{c}}(107.6-138.6)$ & $105.8(91.1-120.5)$ & $114.7^{\mathrm{d}}(104.1-125.3)$ \\
\hline
\end{tabular}

${ }^{\mathrm{a}} p<0.01 ;{ }^{\mathrm{b}} p<0.05$ when compared to birth cohort 1973-1975; ${ }^{\mathrm{c}} p<0.05$ when compared to $1973-1980 ; p<0.001$ when compared to $1973-1975 ;{ }^{\mathrm{d}} p<0.01$ when compared to $1973-1980 ; p<0.001$ when compared to 1973-1975.

MMR, Mumps-measles-rubella 
patients are not correlated with $\mathrm{HbA}_{1 \mathrm{c}}$ levels, ketosis or the loss of body weight at the diagnosis of diabetes suggesting that the metabolic imbalance as such is not sufficient to induce abnormalities in mumps antibody levels $[1,22]$.

The significance of elevated $\operatorname{IgA}$ class mumps antibody levels in patients in the first two series is not known, but it could reflect either an aberrant immunological reactivity or a prolonged course of mumps in these individuals. Serum IgA class mumps antibodies are known to persist much longer than IgM class mumps antibodies after acute infection and prolonged elevation of IgA may be related to chronic or persistent infections. One could speculate that the lack of such IgA elevation in later patient series could be due to the fact that natural mumps was then rare. The parallel decline in IgG class antibodies supports this assumption.

Defective IgG class antibody response to mumps virus in Type 1 diabetic patients may be connected to genetic risk factors for the disease, such as HLA-DR3 which seems to be associated with low cellular immune reactivity against mumps virus in vitro [23]. It may also reflect a general defect in antibody responsiveness as certain other virus antibodies have been shown to be decreased in diabetic subjects $[13,16,22,24,25]$. Such a defect in immune defence may also increase the risk for severe mumps infections and have relevance in the pathogenesis of Type 1 diabetes. This possibility is actually supported by previous studies on sex-related differences in mumps virus specific immune responses - mumps antibody levels are significantly lower in males than in females $[1,12,26]$ whereas complications of mumps are more common in males than in females [27-29]. Interestingly, also the incidence of Type 1 diabetes is higher in boys than in girls $[17,20,21]$.

MMR vaccination has altered the epidemiology of mumps in Finland in two ways. Firstly, it has rapidly eliminated natural infections and secondly, the vaccine virus itself, although attenuated, has increased the number of challenged individuals in young children who otherwise would have not been infected by mumps at that age. Even though the attenuated vaccine virus may be less harmful than the native virus it may have the potential to increase the risk for diabetes in some children. Our observations suggest that in older age groups the effect of vaccination, if any, may have been more protective than harmful, but the question remains open for young children since among very young children, who were the main target population for MMR vaccination, the incidence of Type 1 diabetes has continued to rise until recently in contrast to the older age groups. This rise may, of course, be caused by several factors other than MMR and further studies are needed to explain this phenomenon. Also the possible role of the rubella component of the vaccine should be considered as congenital rubella infections have been shown to be able to induce Type 1 diabetes [30].

Incidence of Type 1 diabetes in children during the $1980 \mathrm{~s}$ indicated no major alterations which could be related to MMR vaccination, but in 1988-1990, approximately 7 years after the last mumps epidemic and 6 years after the MMR vaccinations were started, the continuous rise in diabetes incidence may have ceased. A 2-4-year time lag has previously been described between mumps epidemics and rises in the incidence of diabetes [1-4] suggesting that the present observation period was long enough for the identification of possible mumps related alterations in diabetes incidence rates. However, due to the multiaetiological nature of the disease it is too early to draw final conclusions and the next few years will show whether this plateau in diabetes incidence will continue in Finland. Thus far, comparable studies from other countries where MMR vaccination has been in use have not been published.

Altogether, the observed changes in diabetes incidence rates are relatively small suggesting that so far the eradication of mumps by MMR vaccination has not caused major changes in the epidemiology of Type 1 diabetes in children in Finland. It should be noted, however, that the role of mumps in the pathogenesis, if any, has to be restricted to certain particularly susceptible individuals comprising perhaps only a small percentage of all diabetes cases. Therefore, a possible effect of MMR may be difficult to identify on the basis of incidence data alone. Serological evidence, like the observed shift in mumps antibody levels in the present study, may be a more sensitive marker of such a connection. Further study of the possible connection in children whose MMR vaccination status is precisely known is necessary; such studies are currently in progress.

Acknowledgements. This work was supported by grants from the Foundation for Diabetes Research in Finland, the Reino Lahtikari and the Ahokas Foundations as well as the Tampere City Foundation and the University of Tampere. The Childhood Diabetes in Finland-project has been supported by grants from NIH (DK 37957), the Association of Finnish Life Insurance Companies, Sigrid Jusélius Foundation, the University of Helsinki, the Nordisk Insulin Foundation Committee, and the Juvenile Diabetes Foundation. The expert technical assistance of Ms. E. Jokela and Ms. I. Lehtimäki is gratefully acknowledged.

The Childhood Diabetes in Finland (DiMe) Study Group is composed of the following members:

Principal investigators: Prof. H. K. Akerblom and Prof. J. Tuomilebto

Co-ordinators: R. Lounamaa, L. Toivanen and E. A. Kaprio

Local investigators: A. Fagerlund, M.Flittner, B. Gustafsson, C.Häggqvist, A.Hakulinen, L.Herva, P.Hiltunen, T.Huhtamäki, N.-P. Huttunen, T.Huupponen, M.Hyttinen, T.Joki, R. Jokisalo, M.-L. Käär, S.Kallio, E.A.Kaprio, U.Kaski, M. Knip, L. Laine, J.Lappalainen, J.Mäenpää, A.-L. Mäkelä, K. Niemi, A. Niiranen, A.Nuuja, P.Ojajärvi, T.Otonkoski, K.Pihlajamäki, S.Pöntynen, J. Rajantie, J.Sankala, J.Schumacher, M.Sillanpää, M.-R. Ståhlberg, C.-H. Stråhlmann, T.Uotila, M.Väre, P. Varimo, and G. Wettenstrand.

\section{References}

1. Gundersen, E (1924) Is diabetes of infectious origin ? J Infect Dis 41: 197-202

2. Melin K, Ursing B (1958) Diabetes mellitus as complication of parotitis epidemica (in Swedish). Nord Med 27: 1715-1717

3. Sultz HA, Hart BA, Zielezny M, Schlesinger ER (1975) Is mumps virus an etiologic factor in juvenile diabetes mellitus. J Pediatr 86: 654-656

4. Hyöty H, Leinikki P, Reunanen A et al. (1988) Mumps infections in the etiology of type 1 (insulin-dependent) diabetes. Diabetes Res 9: 111-116 
5. Gamble DR (1980) Relation of antecedent illness to development of diabetes in children. BMJ 281:99-101

6. Prince GA, Jenson AB, Billup L, Notkins AL (1978) Infection of human pancreatic beta cell cultures with mumps virus. Nature 271: 158-161

7. Parkkonen P, Hyöty H, Koskinen L, Leinikki P (1992) Mumps virus infects beta cells in human fetal islet cell cultures upregulating the expression of HLA class I molecules. Diabetologia 35: $63-69$

8. Ratzmann KP, Strese J, Witt S, Berling H, Keilacker H, Michaelis D (1984) Mumps infection and insulin-dependent diabetes mellitus. Diabetes Care 7: 170-173

9. Ratzmann KP, Strese J, Rjasanowski I et al. (1985) Metabolic, hormonal and immunological alterations in subjects with antecedent mumps infection. Exp Clin Endocrinol 86: 323-334

10. Helmke K, Otten A, Willems W (1980) Islet cell antibodies in children with mumps infection. Lancet II: 211-212

11. Helmke K, Otten A, Willems WR et al. (1986) Islet cell antibodies and the development of diabetes mellitus in relation to mumps infection and mumps vaccination. Diabetologia 29: 30-33

12. Hyöty H, Huupponen T, Leinikki P (1985) Humoral immunity against viral antigens in insulin-dependent diabetes mellitus (IDDM) altered $\operatorname{IgA}$ class immune response against mumps virus. Clin Exp Immunol 60: 139-144

13. Toniolo A, Conaldi PG, Garzelli C et al. (1985) Role of antecedent mumps and reovirus infections on the development on type 1 (insulin-dependent) diabetes. Eur J Epidemiol 1: 172-179

14. Peltola H, Karanko V, Kurki T et al. (1986) Rapid effect on endemic measles, mumps, and rubella of nationwide vaccination programme in Finland. Lancet I: 137-139

15. Paunio M (1988) Compliance and vaccination coverage. Health Services Research by the National Board of Health in Finland, Helsinki, No. 47

16. Hyöty H, Räsänen L, Hiltunen M, Lehtinen M, Huupponen T, Leinikki P (1991) Decreased antibody reactivity to Epstein-Barr virus capsid antigen in type 1 (insulin-dependent) diabetes mellitus. APMIS 99: 359-363

17. Tuomilehto J, Lounamaa R, Tuomilehto-Wolf E et al. (1992) Epidemiology of childhood diabetes mellitus in Finland - background of a nationwide study of type 1 (insulin-dependent) diabetes mellitus. Diabetologia 35: 70-76

18. Julkunen I, Hautanen A, Keski-Oja J (1983) Interaction of viral envelope glycoproteins with fibronectin. Infect Immun 40: 876881

19. Hyöty H, Huupponen T, Kotola L, Leinikki P (1986) Humoral immunity against viral antigens in type 1 diabetes: altered $\operatorname{IgA}$ class immune response against coxsackie B4 virus. Acta Path Microbiol Immunol Scand C 94: 83-88
20. Åkerblom HK, Reunanen A (1985) The epidemiology of insulindependent diabetes mellitus (IDDM) in Finland and in northern Europe. Diabetes Care 8 [Suppl 1]: 10-16

21. Reunanen A, Åkerblom HK, Tuomilehto J (1988) High incidence of insulin-dependent diabetes mellitus (IDDM) in children in Finland. Arctic Med Res 47 [Suppl 1]: 535-539

22. Hyöty H, Leinikki P, Hiltunen M, Huupponen T, and the Study Group of Childhood Diabetes in Finland (1990) Virus antibodies in type 1 diabetes in Finland. Diabetologia 33 [Suppl]: A67 (Abstract)

23. Bruserud $\varnothing$, Jervell J, Thorsby E (1985) HLA-DR3 and -DR4 control T-lymphocyte responses to mumps and coxsackie B4 virus: studies on patients with type 1 (insulin-dependent) diabetes and healthy subjects. Diabetologia 28: 420-426

24. Palmer JP, Cooney MK, Ward RH et al. (1982) Reduced coxsackie antibody titres in type 1 (insulin-dependent) diabetic patients presenting during an outbreak of coxsackie B3 and B4 infection. Diabetologia 22: 426-429

25. Diepersloot RJA, Bouter KP, Beyer WEP, Hoekstra JBL, Masurel N (1987) Humoral immune response and delayed type hypersensitivity to influenza vaccine in patients with diabetes mellitus. Diabetologia 30: 397-401

26. Panelius M, Salmi A, Halonen PE, Kivalo E, Rinne UK, Penttinen K (1973) Virus antibodies in serum specimens from patients with multiple sclerosis from siblings and matched controls. Acta Neurol Scand 49: 85-107

27. Fescharek R, Quast U, Maass G, Merkle W, Schwarz S (1990) Measles-mumps vaccination in the FRG: an empirical analysis after 14 years of use. II. Tolerability and analysis of spontaneously reported side-effects. Vaccine 8: 446-456

28. Miller E, Goldacre M, Pugh S et al. (1993) Risk of aseptic meningitis after measles, mumps and rubella vaccine in UK children. Lancet 341: 979-982

29. Koskiniemi M, Rautonen J, Lehtokoski-Lehtiniemi E, Vaheri A (1991) Epidemiology of encephalitis in children: a 20-year survey. Ann Neurology 29: 492-497

30. Rayfield EJ (1990) Effects of rubella virus infection on islet function. Cur Top Microbiol Immunol 156: 63-74

Received: 22 April 1993

and in revised form: 30 June 1993

Dr. H.Hyöty

Department of Biomedical Sciences

University of Tampere

P.O.Box 607

SF-33101 Tampere

Finland 